Abstract-Bycatch and resultant discard mortality are issues of global concern. The groundfish demersal trawl fishery on the west coast of the United States is a multispecies fishery with significant catch of target and nontarget species. These catches are of particular concern in regard to species that have previously been declared overfished and are currently rebuilding biomass back to target levels. To understand these interactions better, we used data from the West Coast Groundfish Observer Program in a series of cluster analyses to evaluate 3 questions: 1) Are there identifiable associations between species caught in the bottom trawl fishery; 2) Do species that are undergoing population rebuilding toward target biomass levels ("rebuilding species") cluster with targeted species in a consistent way; 3 ) Are the relationships between rebuilding bycatch species and target species more resolved at particular spatial scales or are relationships spatially consistent across the whole data set? Two strong species clusters emergeda deepwater slope cluster and a shelf cluster-neither of which included rebuilding species. The likelihood of encountering rebuilding rockfish species is relatively low. To evaluate whether weak clustering of rebuilding rockfish was attributable to their low rate of occurrence, we specified null models of species occurrence. Results indicated that the ability to predict occurrence of rebuilding rockfish when target species were caught was low. Cluster analyses performed at a variety of spatial scales indicated that the most reliable clustering of rebuilding species was at the spatial scale of individual fishing ports. This finding underscores the value of spatially resolved data for fishery management.

Manuscript submitted 19 January 2013. Manuscript accepted 25 November 2013. Fish. Bull. 112:36-48 (2014).

doi: 10.7755/FB.112.1.3

The views and opinions expressed or implied in this article are those of the author (or authors) and do not necesarily reflect the position of the National Marine Fisheries Service, NOAA.

\title{
Co-occurrence of bycatch and target species in the groundfish demersal trawl fishery of the U.S. west coast; with special consideration of rebuilding stocks
}

\author{
Eliza Heery (contact author) ${ }^{1}$ \\ Jason M. Cope ${ }^{2}$ \\ Email address for contact author: eliza.heery@uw.edu \\ 1 Pacific States Marine Fisheries Commission \\ Northwest Fisheries Science Center \\ National Marine Fisheries Service, NOAA \\ 2725 Montlake Boulevard East \\ Seattle, Washington 98122-2097 \\ Present address: Department of Biology \\ University of Washington \\ Box 351800 \\ Seattle, Washington 98195 \\ 2 Fisheries Resource Analysis and Monitoring Division \\ Northwest Fisheries Science Center \\ National Marine Fisheries Service, NOAA \\ 2725 Montlake Boulevard East \\ Seattle, Washington 98122-2097
}

Bycatch, catch of incidental (nontarget) species, is a major source of fish removals, and thus is a concern in fisheries around the world. Its impact on biodiversity and habitat health may be extensive (Dayton et al., 1995; Collie et al., 1997; Jennings and Kaiser, 1998; Thrush and Dayton, 2002), and, consequently, it has the potential to affect the longterm sustainability of marine fisheries and ecosystems. Several articles have emphasized the need for ecosystem management to address the population health of both targeted and nontarget species (Pauly et al., 2000; Pikitch et al., 2004; Beddington et al. 2007). A comprehensive understanding of the species composition and characteristics of bycatch could contribute to a greater knowledge of the effects of marine fisheries on ecosystems (Goni, 1998).

Bycatch is particularly pertinent for multispecies fisheries, where the gear often cannot fully separate targeted and nontarget species. The groundfish fishery on the west coast of the United States (Fig. 1) is a multispecies fishery that primarily targets demersal fish species such as Sablefish (Anoplopoma fimbria), Dover Sole (Microstomus pacificus), Shortspine Thornyhead (Sebastolobus alascanus), Petrale Sole (Eopsetta jordani), and Pacific Hake (Merluccius productus). The majority of catch is acquired through the use of bottom-trawl nets, which are considered one of the least discriminating gear types (Alverson et al., 1994). The depths at which fish are caught and from which fish are raised to the ocean surface also cause mortality. Despite the long history of bottomtrawl fishing on the west coast of the United States, information on the species composition of bycatch in this fishery has only recently been regularly collected (Bellman and Heery, 2013).

A clear understanding of species co-occurrence in the total catch is important for anticipating the ecological impacts of bycatch. Since 2002, bycatch data have been collected in the bottom trawl (non-hake) fishery by at-sea observers and are used by fishery managers in a variety of ways. Perhaps the most important 


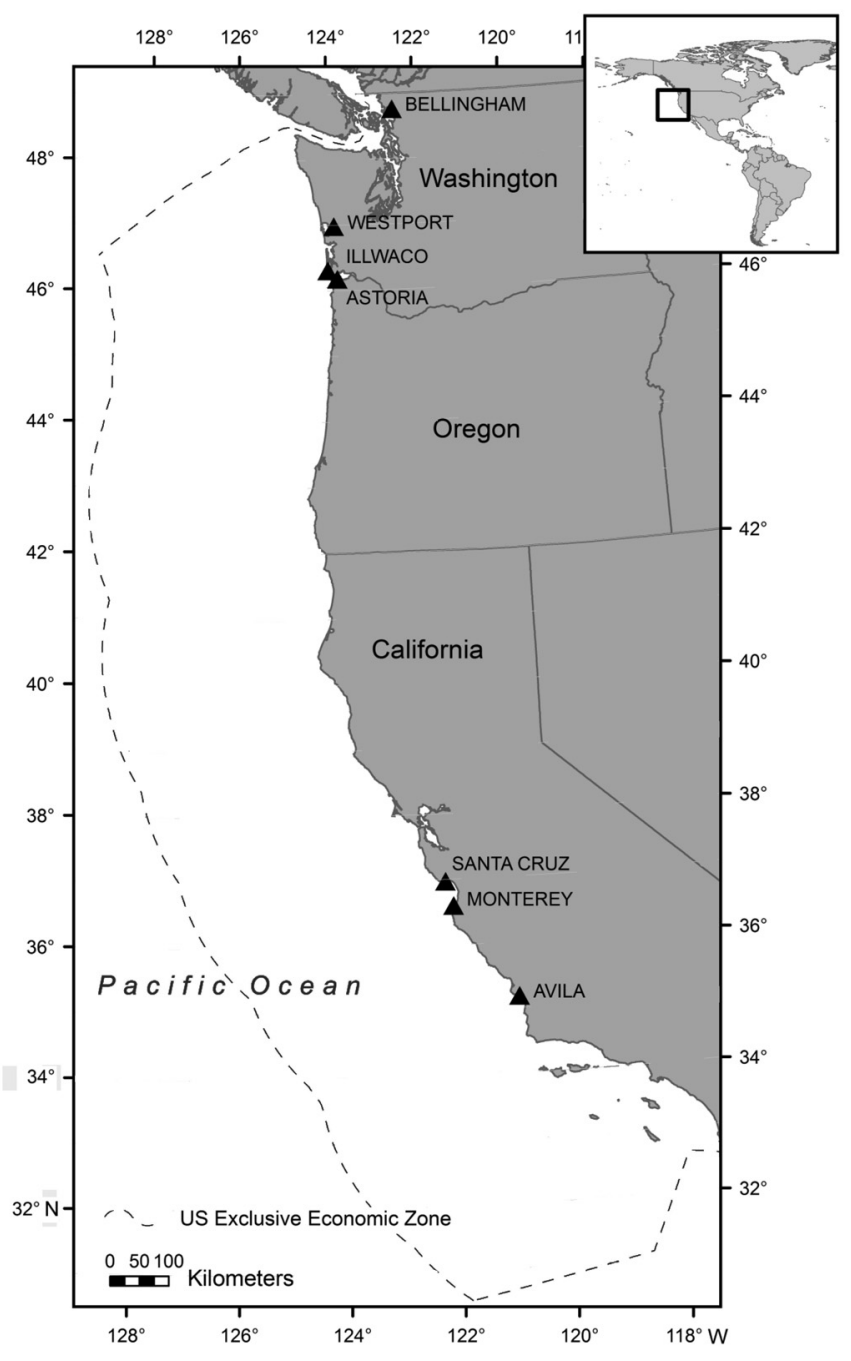

Figure 1

Map of the study area from northern Washington to southern California where catch data were collected by observers from 2002 to 2009 . In cluster analyses, clusters containing rebuilding species were most evident when the data for each port were evaluated separately. The map highlights examples of port groups in which relationships between rare rebuilding rockfish and target species were identified in the commercial catch. Courtesy of M. Bellman.

role of observer data for management is for the calculation of bycatch ratios. Bycatch ratios reflect the amount of catch of incidental (nontarget) species that occurs in relation to the amount of retained catch of species that are targeted by the fishery. Managers produce projected estimates of bycatch for nontarget species on the basis of such ratios in conjunction with anticipated landings (Bellman and Heery, 2013). This approach assumes that there is a proportional relationship between bycatch and landings of target species (Rochet and Trenkel, 2005).
Several previous studies have examined assemblages among groundfish species through the use of data from fishery-independent surveys (Gabriel and Tyler, 1980; Weinberg, 1994; Jay, 1996; Williams and Ralston, 2002; Tolimieri and Levin, 2006; Zimmerman, 2006; Cope and Haltuch, 2012). There have been fewer studies of species associations with the use of fisherydependent data. Lee and Sampson (2000) used logbook data to evaluate species composition in the bottom trawl fishery. Trawl logbooks are maintained by vessel captains and include only species that are retained and landed. Their study, therefore, did not include species that were also caught by trawl nets but that were discarded because of economic or regulatory constraints. Rogers and Pikitch (1992) used observer data to identify species assemblages, but participation in the observer program that produced their data was voluntary. The data available for that study were collected between 1985 and 1987, a period in which fishery practices and regulations differed considerably from those used more recently.

This study presents a current view of species cooccurrence onboard commercial vessels in the bottom trawl fishery, and with the use of data from a mandatory at-sea observer program conducted yearly from 2002 to 2009, is more comprehensive than that of previous studies. Three major questions were explored: 1) Are there identifiable associations between species caught in the bottom trawl fishery? 2) Do species that are undergoing population rebuilding toward target biomass levels ("rebuilding species") cluster with targeted species in a consistent way? 3) Are the relationships between rebuilding species and target species more resolved at particular spatial scales or are relationships spatially consistent across the whole data set? All groundfish species that were managed under federal rebuilding plans during the study period were considered as rebuilding species. The results from our analysis relate indirectly to species assemblages in the marine environment. However, the study is primarily relevant in the context of fisheries management because it provides insight into the relationship between bycatch of nontarget species and catch of targeted species in the commercial catch of the demersal trawl fishery on the west coast of the United States.

\section{Materials and methods}

\section{At-sea observer data}

Observer data were obtained from the West Coast Groundfish Observer Program (WCGOP), part of the National Marine Fisheries Service (NMFS). The WCGOP employs a stratified multistage random sampling design in which permits for the coastwide limited entry trawl fishery are selected for 2-month periods without replacement until all permits in the fleet are observed. The vast majority of permits were linked to individual 
vessels during the study period. Information on switching of permits between vessels could not be disclosed for the few instances when it occurred, for reasons of confidentiality, but the distinction between permits and vessels is not important for our study. Data were collected on all trips and tows within the 2-month period for which a permit was selected. The data used for this analysis were collected from January 2002 through December 2009. During this period, the observer program cycled through all nonexempt permits (exemptions were given because of safety concerns) in the limited entry bottom trawl fleet 10 times.

While onboard, observers quantified the total discard weight of each species on each tow and collected biological samples from discards through subsampling procedures that are documented elsewhere $\left(\mathrm{NWFSC}^{1}\right)$. Observers focused their attention foremost on discarded catch because data on discards could not be obtained from other sources, unlike landed catch for which data were available from vessel logbooks and landing receipts. Retained catch weights were acquired from the vessel logbook or by visual estimation of the proportion of the codend or trawl alley (the area where the trawl is placed after retrieval) that was filled. These estimates were then reconciled with weights from landing receipts for each observed trip. Through this process of reconciling the 2 data sources, changes were made to the retained weights on $94 \%$ of observed trips. When landings records were not available for an observed trip, retained weights originally recorded by the observer were used. Further information regarding the sampling scheme and data quality control process are available online at http://www.nwfsc.noaa.gov/research/ divisions/fram/observer/.

To begin our analysis, presence and absence information for each tow was compiled from the observer data set. Although abundance data would give information on the magnitude of bycatch, the use of abundance data for our analysis would yield associations primarily between species that co-occur at similar catch levels. Although interesting for other research questions, those abundance-dominated associations were not informative for our analysis of co-occurrence of rebuilding bycatch species and target species. Additional available fields that were used in the analysis included average latitude, longitude, average depth, departure and return ports, and tow duration, among others. The data contained catch information for 175 different species from 45,252 tows. All groundfish species that occurred in at least $5 \%$ of tows or more were included, eliminating 138 species from the analysis that were not the target and rebuilding bycatch species of interest for our study. In addition, 7 species designated as "overfished" by NMFS were considered in the analysis. Under fed-

\footnotetext{
${ }^{1}$ NWFSC (Northwest Fisheries Science Center). 2007. West coast groundfish observer training manual. [Available from NWFSC West Coast Groundfish Observer Program, 2725 Montlake Blvd. East, Seattle, WA 98112.]
}

eral law, a rebuilding plan must be developed for any fish species that is designated as "overfished" in relation to limit reference points (standardized thresholds used to determine stock status) (Restrepo et al., 1998). These species included Bocaccio (Sebastes paucispinis), Canary Rockfish (S. pinniger), Cowcod (S. levis), Darkblotched Rockfish (S. crameri), Pacific Ocean Perch ( $S$. alutus), Widow Rockfish (S. entomelas), and Yelloweye Rockfish (S. ruberrimus).

\section{Cluster analysis}

Cluster analyses are commonly used to identify fish species assemblages (Williams and Ralston, 2002). Many approaches to clustering analysis exist and resultant groupings are always relative to the units being grouped and the algorithm used to process the distance matrix (Gordon, 1999). Multiple methods of clustering the data were used to make results and conclusions more robust (Mahon et al., 1998). We focused on 2 main approaches: 1) Hierarchical agglomerative cluster analysis (HCA) and 2) Nonhierarchical cluster analysis, or partitioning analysis (PA) (Cope and Haltuch, 2012).

With the HCA approach, all elements are assumed to be a separate cluster and groups are established by subsequently merging elements to maximize the average distances between all elements within each cluster. Partitioning analysis, with the $k$-medoids approach, requires specifying beforehand the number of desired clusters from which the grouping algorithm minimizes dissimilarity between elements within clusters (Cope and Punt, 2009). Partitioning analysis thus requires the additional step of identifying the optimal number of clusters $(k)$ supported by the data. This step is accomplished by using cluster validity diagnostics. After considering several of them through simulation, Cope and Punt (2009) found 2 cluster validity diagnostics that performed best: average silhouette coefficient (Kauffman and Rousseeuw, 2005) and Hubert's $\Gamma$ (Gordon, 1999). Because these diagnostics have a tendency to either overlump or oversplit groups, respectively, both of them were used to identify the optimal number of clusters. In instances where the 2 diagnostics supported different numbers of optimal clusters, both sets of clusters were retained for evaluation. The Bray-Curtis dissimilarity measure was used to transform species presence and absence information by tow into a dissimilarity matrix used by both clustering approaches.

Once species were clustered, the next task was to identify which of the clusters were dissimilar enough from others to be considered distinct. Guidance for interpreting the clusters in a PA was provided in Kauffman and Rousseeuw (2005), who identified an average group silhouette value $>0.25$ as being sufficiently distinct from other groups. For the HCA, it was less clear what constituted a group. We followed the approach of Cope and Haltuch (2012) who introduced a null model approach to define significant groups when using HCA. 
This approach added "fake" species (termed "fakies") to the data set that were randomly allocated to each tow (i.e., a 0.5 probability of occurring in any tow) and were subsequently clustered as members of the full data set. The dissimilarity point at which these species were grouped (termed the "breakpoint") represented the dissimilarity distance at which group assignments were considered to be no better than random placement. This breakpoint was not affected by the number of fakies included in the analyses (Cope and Haltuch, 2012). Here the results are presented for cases where 5 fakies were added.

Results from the HCA and the PA (with the use of both the silhouette coefficient and Hubert's $\Gamma$ cluster validity diagnostics) were then compared and reconciled. Reconciliation was performed by looking for consistently forming groups of co-occurring species in the catch that were supported by all clustering methods. Instances of groups being supported by 1 , but not both, cluster approaches were noted. Throughout the presentation of our results, we use the term "identifiable" clusters to represent clustered species that 1) had an average silhouette value $>0.25$ in each PA (Kauffman and Rousseeuw, 2005) and 2) a dissimilarity point that was less than that for simulated fake species in HCA results (Cope and Haltuch, 2012).

Species assemblage analyses were completed on various subsets of the data to evaluate species cooccurrence in the demersal trawl fishery at a variety of temporal and spatial scales. These analyses helped to resolve fine-scale aspects of species co-occurrence with rebuilding species in the commercial catch. Assemblages were first evaluated on a coastwide basis by applying each clustering method to the data as a whole. The next part of the analyses partitioned the data by year. Additionally, dominant clusters sometimes obscured smaller, but nonetheless identifiable groupings. To avoid such an outcome, we removed the ubiquitous species that had formed clusters when using all species combined and then ran all cluster analyses again with the remaining species to identify additional assemblages.

\section{Rebuilding species}

The characterization of species assemblages containing rebuilding species was an important consideration, yet the rebuilding species were some of the rarest of the species included in our data set. Thus, it was unlikely that they would be well represented in any assemblage. Three approaches were taken to resolve the cooccurring relationship of rebuilding species with other species in the commercial catch data. With the first approach, we compared the proximity of rebuilding species with that of the simulated fakies that occurred with decreasing frequency. Cluster analyses were explored with the occurrence probability of fakies on each tow $(x)$ set equal to the frequency of occurrence of each rebuilding species (Table 1 ). This exploration allowed evaluation of the level of random assignment which best described the presence of rebuilding species in clusters. For example, if a species had a 5\% frequency of occurrence, a probability of assigning a fakie to a tow was also set at 5\%. A dissimilarity distance equal to or greater than the breakpoint of the fakies would indicate a randomly occurring, and therefore not a cooccurring, rebuilding species.

With the second approach, we considered species co-occurrences only in the rare occasions when a rebuilding species was present on a tow, thus defining species assemblages as conditional on the presence of a rebuilding species. Using only positive tows for each rebuilding species as data sets, we re-analyzed clusters, and species assemblages were identified on a coastwide, year-by-year basis. Fakies were also incorporated into this analysis to define clusters.

With the third approach, we evaluated species assemblages at finer spatial resolutions to identify spatially explicit co-occurrences with rebuilding species in the catch. For each rebuilding species, a tree regression was applied to identify a spatial stratification scheme on the basis of latitude. Tree regression uses recursive partitioning to split data into groups (Clark and Pregibon, 1992). In this case, the data were split by latitude on the basis of the log-transformed catch per tow of each rebuilding species and thus identified hot spots of species catch. Cluster analysis was then applied within each of the resulting latitudinal strata. Additionally, data were stratified with $1^{\circ}$ latitude intervals, as well as on the basis of the departure port recorded by the observer. Clustering results from these 3 stratification schemes were then compared and summarized.

All analyses described here were conducted in $\mathrm{R}$ software (vers. 2.13.2; R Development Core Team, 2011²).

\section{Results}

\section{Overall species co-occurrences}

When using observer data from all areas and all years, we found 2 strong and consistent clusters: 1) a deepwater slope cluster and 2) a shelf cluster (Table 2, Fig. 2). The most common components of the slope cluster were Sablefish, Dover Sole, and Shortspine Thornyhead. This group also included Arrowtooth Flounder (Atheresthes stomias), Rex Sole (Glyptocephalus zachirus), Longnose Skate (Raja rhina), and Pacific Hake, depending on the method used to determine clusters. The major constituents of the shelf cluster were English Sole (Parophrys vetulus) and Petrale Sole. Hierarchical clustering analysis also indicated that Lingcod (Ophiodon elongatus), Pacific Spiny Dogfish (Squalus suckleyi), and Spotted Ratfish (Hydrolagus colliei) were

\footnotetext{
${ }^{2}$ Mention of trade names or commercial companies is for identification purposes only and does not imply endorsement by the National Marine Fisheries Service, NOAA.
} 


\section{Table 1}

Groundfish species that were included in cluster analyses and the percentage of "inshore" and "offshore" tows during which they were observed for the period of 2002-09 in the groundfish fishery of the U.S. west coast. Inshore was defined as all tows occurring at an average depth of $274 \mathrm{~m}$ (150 fathoms) or less. Offshore tows were those for which the average depth was greater than 150 fathoms. Rebuilding rockfish species and their respective percentages on inshore and offshore tows are underlined. Major target species are noted by an asterisk.

\begin{tabular}{|c|c|c|c|}
\hline Common name & Scientific name & $\begin{array}{c}\% \text { of } \\
\text { inshore tows }\end{array}$ & $\begin{array}{c}\% \text { of } \\
\text { offshore tows }\end{array}$ \\
\hline Arrowtooth Flounder* & Atheresthes stomias & 64.5 & 55.7 \\
\hline Aurora Rockfish & Sebastes aurora & 0.7 & 25.9 \\
\hline Big Skate & Raja binoculata & 26.8 & 1.3 \\
\hline Bocaccio & Sebastes paucispinis & $\underline{5.3}$ & $\underline{0.9}$ \\
\hline Canary Rockfish & Sebastes pinniger & $\underline{18.2}$ & $\underline{0.6}$ \\
\hline Cowcod & $\underline{\text { Sebastes levis }}$ & $\underline{1.3}$ & $\underline{0.1}$ \\
\hline Darkblotched Rockfish & Sebastes crameri & $\underline{15.7}$ & $\underline{18.2}$ \\
\hline$\overline{\text { Dover Sole* }}$ & Microstomus pacificus & $\overline{75.1}$ & $\overline{93.0}$ \\
\hline English Sole* & Parophrys vetulus & 80.7 & 10.5 \\
\hline Flathead Sole & Hippoglossoides elassodon & 20.5 & 0.1 \\
\hline Greenstriped Rockfish & Sebastes elongatus & 28.4 & 1.3 \\
\hline Grenadiers & Macrouridae & 0.4 & 12.8 \\
\hline Lingcod & Ophiodon elongatus & 65.2 & 9.4 \\
\hline Longnose Skate* & Raja rhina & 48.3 & 48.3 \\
\hline Longspine Thornyhead* & Sebastolobus altivelis & 0.3 & 60.9 \\
\hline Mixed Thornyheads* & Sebastolobus spp. & 0.3 & 13.0 \\
\hline Other rockfish & Sebastes spp. & 6.9 & 28.0 \\
\hline Other sanddabs & Citharichthys spp. & 33.4 & 0.1 \\
\hline Other skates & Rajiformes & 61.4 & 40.0 \\
\hline Pacific Cod & Gadus macrocephalus & 28.2 & 1.0 \\
\hline Pacific Flatnose & Antimora micolepis & 0.0 & 21.3 \\
\hline Pacific Grenadier & Coryphaenoides acrolepis & 0.0 & 22.6 \\
\hline Pacific Hake & Merluccius productus & 56.0 & 70.9 \\
\hline Pacific Halibut & Hippoglossus stenolepis & 44.8 & 22.6 \\
\hline Pacific Ocean Perch & Sebastes alutus & $\underline{2.5}$ & $\underline{15.8}$ \\
\hline Pacific Sanddab & Citharichthys sordidus & 48.7 & 0.5 \\
\hline Petrale Sole* & Eopsetta jordani & 85.7 & 22.4 \\
\hline Redbanded Rockfish & Sebastes babcocki & 2.5 & 13.0 \\
\hline Rex Sole* & Glyptocephalus zachirus & 81.6 & 47.7 \\
\hline Rosethorn Rockfish & Sebastes helvomaculatus & 2.3 & 9.0 \\
\hline Sablefish* & Anoplopoma fimbria & 50.0 & 95.2 \\
\hline Shortspine Thornyhead* & Sebastolobus alascanus & 5.4 & 87.8 \\
\hline Pacific Spiny Dogfish & Squalus suckleyi & 57.7 & 33.9 \\
\hline Splitnose Rockfish & Sebastes diploproa & 4.4 & 30.5 \\
\hline Spotted Ratfish & Hydrolagus colliei & 70.9 & 30.0 \\
\hline Widow Rockfish & $\underline{\text { Sebastes entomelas }}$ & $\underline{1.9}$ & $\underline{1.6}$ \\
\hline Yelloweye Rockfish & $\overline{\text { Sebastes ruberrimus }}$ & $\overline{1.3}$ & $\overline{0.1}$ \\
\hline
\end{tabular}

part of the shelf cluster, but this result was not confirmed by partitioning analysis. These groups were consistent with those found by Cope and Haltuch (2012), who used fishery-independent data. Species were identified as slope or shelf species on the basis of their depth distribution in the groundfish bottom trawl survey (Keller et al., 2012).

All of the species shown to cluster in this first round of analysis were relatively common, occurring on at least $35 \%$ of tows (Table 1 ). These species were the only ones to form clusters more readily than fakies, which were grouped at a silhouette value just above 0.25 in each PA (consistent with the recommendation of Kauffman and Rousseeuw [2005]) and at a distance of approximately 0.4 in the HCA (consistent with Weinberg [1994]). Rebuilding and less common species were not components of clusters at a coastwide level and clustered less readily than fakies, which had been simulated to occur at random.

Similar trends were observed when the data were broken out by year. Only the most common species formed clusters more readily than fakies on an annual, 


\section{Table 2}

Results from hierarchical agglomerative cluster analyses (HCAs) of groundfish species and simulated, random fake species ("fakies"). Only species that formed groups more readily than fakies are included. Species that exhibited the strongest association with other species in their respective group are set in italic type. Groups A, C, and D included species commonly associated with the continental slope, and group B included species associated with shelf habitats. Note that the "skates" category included Longnose Skate from 2002 to 2004, causing it to cluster with slope species. Longnose Skate were recorded under a distinct species code starting in 2005 .

\begin{tabular}{|c|c|c|c|c|c|c|c|c|}
\hline Species & 2002 & 2003 & 2004 & 2005 & 2006 & 2007 & 2008 & 2009 \\
\hline Dover Sole & $\mathrm{A}$ & A & $\mathrm{A}$ & A & A & A & A & A \\
\hline Sablefish & A & A & A & A & A & A & A & A \\
\hline Pacific Hake & A & A & A & A & A & A & A & A \\
\hline Arrowtooth Flounder & $\mathrm{A}$ & $\mathrm{A}$ & $\mathrm{A}$ & $\mathrm{A}$ & $\mathrm{A}$ & A & A & A \\
\hline Skates & A & A & A & & & & & \\
\hline Longnose Skate & & & & $\mathrm{A}$ & $\mathrm{A}$ & $\mathrm{A}$ & $\mathrm{A}$ & $\mathrm{A}$ \\
\hline Rex Sole & A & A & A & B & B & A & & \\
\hline Petrale Sole & B & B & B & B & B & B & B & B \\
\hline English Sole & B & B & B & B & B & B & B & B \\
\hline Lingcod & B & B & B & B & B & B & & B \\
\hline Spotted Ratfish & $\mathrm{B}$ & $\mathrm{B}$ & $\mathrm{B}$ & $\mathrm{B}$ & $\mathrm{B}$ & $\mathrm{B}$ & & \\
\hline Pacific Sanddab & B & & & & & & & B \\
\hline Pacific Spiny Dogfish & & & & B & B & B & & \\
\hline Longspine Thornyhead & $\mathrm{C}$ & $\mathrm{A}$ & $\mathrm{C}$ & $\mathrm{C}$ & $\mathrm{C}$ & & $\mathrm{A}$ & $\mathrm{A}$ \\
\hline Shortspine Thornyhead & $\mathrm{C}$ & A & $\mathrm{C}$ & $\mathrm{C}$ & $\mathrm{C}$ & $\mathrm{A}$ & A & A \\
\hline Pacific Flatnose & & & & & $\mathrm{D}$ & & & \\
\hline Pacific Grenadier & & & & & $\mathrm{D}$ & & & \\
\hline
\end{tabular}

coastwide basis. The 2 major clusters identified in the run with combined areas over all years were generally recognized annually as well (Table 2). Dover Sole, Sablefish, Pacific Hake, and Arrowtooth Flounder consistently clustered together in all years. Skates were also grouped with these species in 2002 through 2004. From 2005 through 2009, Longnose Skate was instead clustered with the Dover Sole+Sablefish group. This occurrence is likely due to a shift in the way skate species were recorded in the observer data. Before 2005, Longnose Skate were given the species code for the unspecified skate category.

Shortspine Thornyhead and Longspine Thornyead were only part of the cluster of slope species in some years during the time series (Table 2). In 2002, 2004, 2005, and 2006, they formed a cluster with each other and with no other species. Petrale Sole and English Sole formed a consistent group in all years. Depending on the year, they were also grouped with Lingcod, Spotted Ratfish, Rex Sole, Pacific Spiny Dogfish, and Pacific Sanddab (Citharichthys sordidus) (Table 2).

When ubiquitous species that formed an identifiable assemblage on a coastwide basis were removed from the data and the analysis of all years of data was rerun, no further groupings were identified to cluster more readily than were the fakies. The same was true when identified assemblages were removed from the data and analyses were conducted separately for each year.

\section{Rebuilding bycatch species}

We used 2 data treatments to discern co-occurrences of rebuilding species with other species in trawl catch. In the first treatment, simulated fakies were introduced at frequencies of occurrence that matched those of the respective rebuilding species. This step was taken to evaluate whether the rebuilding species grouped in a better-than-expected manner on the basis of frequency of occurrence alone. Bocaccio, Cowcod, Canary Rockfish, Darkblotched Rockfish, Pacific Ocean Perch, and Widow Rockfish all formed groups with target species more readily than did fakies that were simulated on the basis of the percent occurrence of each rebuilding species. This observation indicates the tendency for rebuilding species to cluster more than expected from their low encounter rates. Yelloweye Rockfish, which occurred in $0.6 \%$ of tows, was the only rebuilding rockfish species that did not form groups more than the simulated fakies.

With the second treatment, we evaluated whether rebuilding species formed clusters with any other species, using only the positive occurrence data for the rebuilding species in question (i.e., only tows where that rebuilding species was encountered). An example for Canary Rockfish is presented in Figure 3. In all cases, this step resulted in one large cluster that inevitably contained the rebuilding species in question, along with those species that occur most commonly in the bottom 


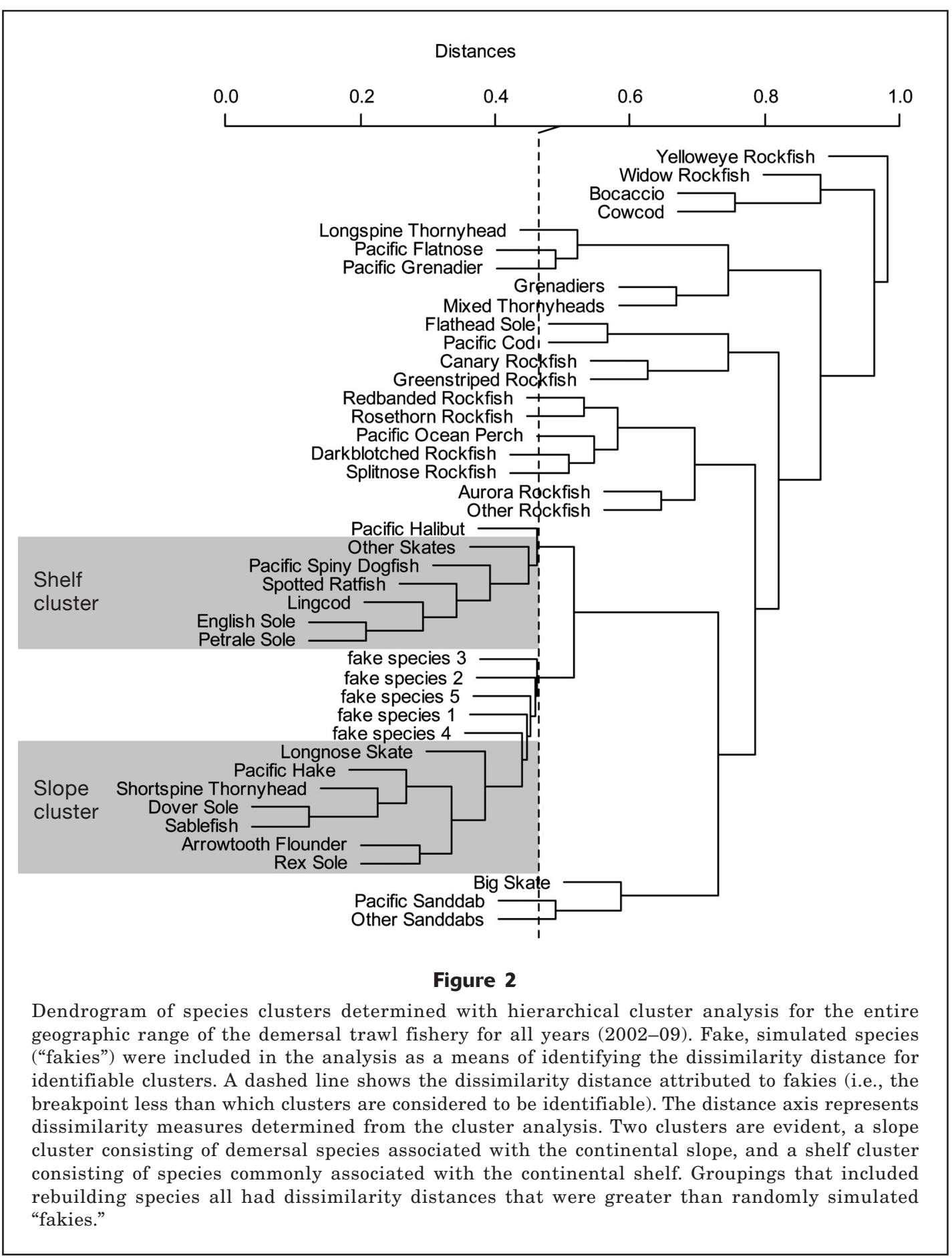

trawl fishery. Rebuilding species that are associated with continental shelf habitats (Canary Rockfish, Yelloweye Rockfish, and Bocaccio) did tend to cluster more closely with shelf target species such as English Sole, Petrale Sole, and Lingcod. However, they were all still part of a larger cluster that also included Sablefish, Dover Sole, and other slope species. These large clusters had a silhouette value $<0.25$ (for PA analyses) and a distance measure less than 0.4 (for HCA), both indicating insignificant groupings. Rebuilding species were grouped with the most common species by default. When a rebuilding species was caught, a series of other commonly occurring target species were likely to have been caught as well, but the opposite could not be stated. As an example, a tow in which Canary Rockfish was caught was also likely to have caught Petrale 


\section{Table 3}

Results from tree regressions for 5 rare rebuilding rockfish species. Tree regressions were conducted for each rebuilding species that did not form identifiable clusters in initial cluster analyses in which all species were included and were used to develop strata boundaries for additional cluster analyses. A minimum sample size of 100 tows was required within each stratum. Strata selected from the tree regression produced the same clustering results that were observed when data from the entire coast were analyzed: No clusters containing rebuilding species were evident.

\begin{tabular}{ll}
\hline Species & \multicolumn{1}{c}{ Stratification } \\
\hline Bocaccio & $46^{\circ} 39.62^{\prime}, 39^{\circ} 53.32^{\prime}$, and $38^{\circ} 47.20^{\prime} \mathrm{N}$ latitude \\
Canary Rockfish & $47^{\circ} 13.70^{\prime}, 46^{\circ} 10.72^{\prime}$, and $45^{\circ} 13.19^{\prime} \mathrm{N}$ latitude \\
Cowcod & No suitable strata \\
Widow Rockfish & $46^{\circ} 05.49^{\prime}$ and $40^{\circ} 32.46^{\prime} \mathrm{N}$ latitude \\
Yelloweye Rockfish & $47^{\circ} 43.28^{\prime}$ and $46^{\circ} 13.53^{\prime} \mathrm{N}$ latitude
\end{tabular}

Sole, English Sole, and Lingcod, but catch of these 3 species did not serve as an indicator for the potential of encountering Canary Rockfish (Fig. 3).

Next we evaluated whether rebuilding species were part of recognizable species assemblages at a finer spatial resolution. This step was undertaken by conducting 3 sets of cluster analyses that had been stratified 1) by using tree regression, 2) by using $1^{\circ}$ latitudinal strata, and 3) by departure port. Results from the tree regression used to divide tows into latitudinal strata are shown in Table 3. Strata selected from the tree regression produced the same clustering results that were observed when data from the entire coast were analyzed: no clusters containing rebuilding species were evident. The large size of latitudinal strata identified by tree regression may explain the similarity of these results to the coastwide data results.

To evaluate species assemblages on an even finer scale, the data were divided into smaller latitudinal strata ( $1^{\circ}$ intervals). At this spatial resolution rebuilding bycatch species formed clusters in 1 area, between $35^{\circ}$ and $36^{\circ}$ north latitude, where Bocaccio was grouped with English Sole (Table 4). PA results indicated that the Widow Rockfish was also a part of this assemblage, but this finding was not confirmed by HCA. This area contained a relatively small number of observations with a total of 367 observed tows across all years. In other areas, there did appear to be a loose relationship between Canary Rockfish and Greenstriped Rockfish (Sebastes elongatus). However, this result was not confirmed by all clustering methods and, therefore, was not recognized as a meaningful result, particularly given that Greenstriped Rockfish is not a targeted species.

Clusters containing rebuilding species were more evident when the data were stratified by departure port. Table 5 details the results of cluster analysis for each port group separately. Rebuilding species formed clusters in several southern port groups. However, the sample size for these ports was also relatively small. For instance, Bocaccio grouped with several slope species, including Sablefish, Dover Sole, and Pacific Hake, when caught by 6 different vessels originating in Santa Cruz and Monterey. All together, these vessels made a total of 294 observed tows (out of 27,162 total tows coastwide) from 2002 through 2009. Additionally, Cowcod was associated with Pacific Sanddab (Citharichthys sordidus) in the catch of observed vessels from Avila. These vessels, 7 in total, made 108 observed tows throughout the entire time series.

Farther to the north, vessels departing from Astoria, Westport, and Ilwaco (Fig. 1) tended to catch Pacific Ocean Perch with 2 nonrebuilding slope rockfish species: Redbanded Rockfish ( $\mathrm{Se}$ bastes babcocki) and Splitnose Rockfish (S. diploproa). This slope rockfish cluster was distinct from the slope species assemblage of Sablefish, Dover Sole, and others (Table 5). For Bellingham vessels, the slope rockfish assemblage also included Darkblotched Rockfish.

\section{Discussion}

In this analysis, we sought to identify whether there were consistently observed associations between target and nontarget species in commercial catches monitored by fisheries observers, who are the source of data usually available to fishery managers for bycatch, or whether the species composition in the commercial catch might be better described as random. We placed particular emphasis on the bycatch of rare, but important rebuilding species. Such bycatch of rebuilding species can delay recovery of overfished stocks and limit target fisheries. When evaluating data from the entire geographic range of the fishery, we found 2 distinct species assemblages that consistently grouped more readily than did randomly simulated fakies: a deepwater slope group characterized by Dover Sole and Sablefish and a shallower shelf group dominated by English Sole and Petrale Sole (Fig. 2).

Distinct groups of deepwater slope and shelf species have been a consistent finding in studies of species assemblages among west coast groundfish (Gabriel and Tyler, 1980; Rogers and Pikitch, 1992; Jay, 1996; Lee and Sampson, 2000; Tolimieri and Levin, 2006; Zimmerman, 2006; Cope and Haltuch, 2012). The study of Rogers and Pikitch (1992) is perhaps the most similar to our study, because of their use of observer data and similar quantitative methods. The shelf assemblage identified by Rogers and Pikitch (1992) included sanddabs, English Sole, Sand Sole (Psettichthys melanostictus), Starry Flounder (Platichthys stellatus), 


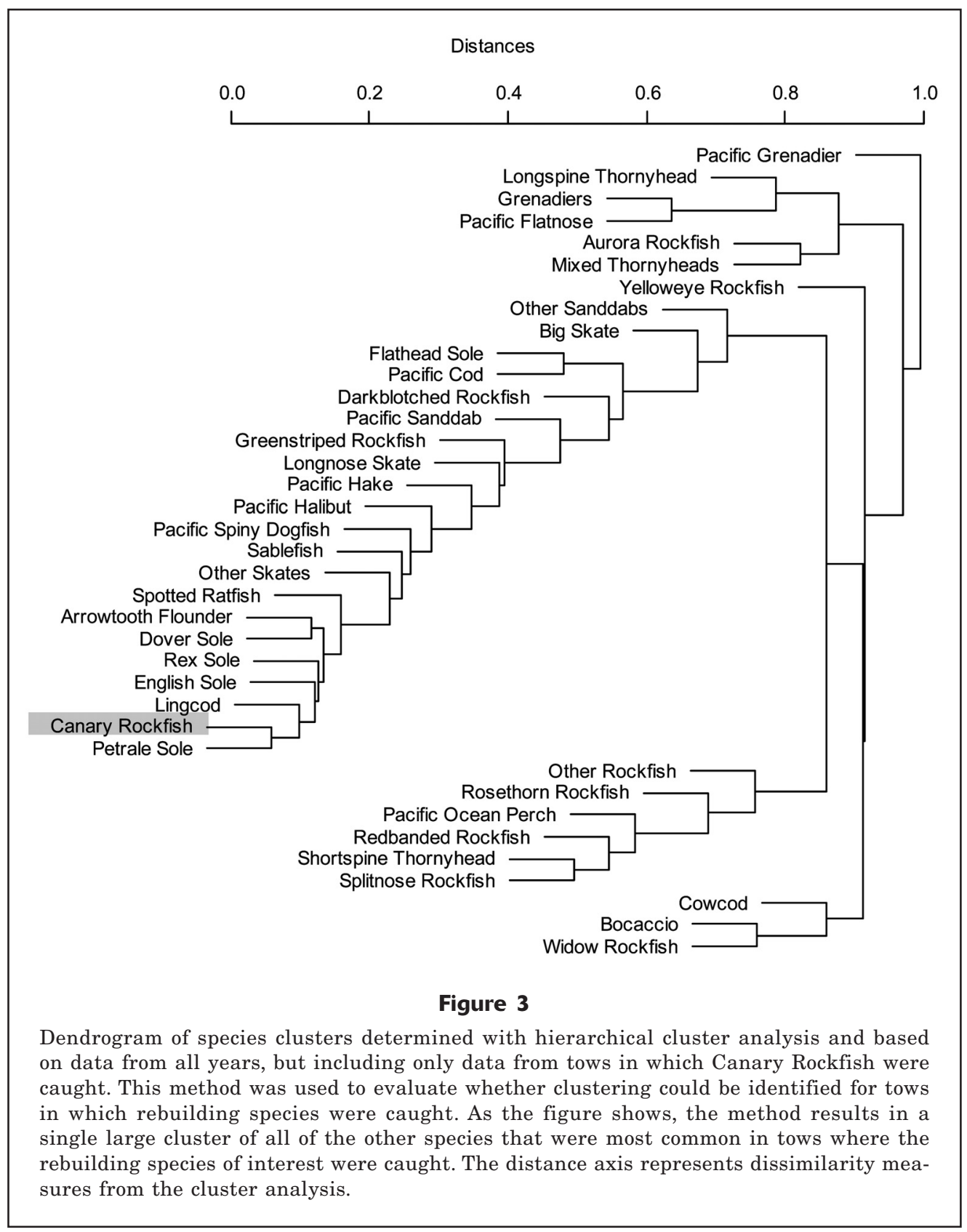

and Petrale Sole. Sand Sole and Starry Flounder were not included in the current analysis because they occurred on fewer than 5\% of observed tows. However, the other components of this assemblage were consistent with our findings. Rogers and Pikitch (1992) identified 2 deepwater assemblages, 1 consisting primarily of Sablefish and Dover Sole, and a second that included Darkblotched Rockfish, Pacific Ocean Perch, Splitnose Rockfish, Yellowmouth Rockfish (Sebastes reedi), and Sharpchin Rockfish ( $S$. zacentrus). The results presented here were similar when data from port groups along the northern coast were analyzed. These similarities are expected because the data used by Rogers and Pikitch (1992) were collected between $42^{\circ} 60^{\prime}$ and $48^{\circ} 42^{\prime}$ north latitude.

Contrary to the current analysis, Rogers and Pikitch (1992) found that 3 of the rockfish now identified as rebuilding species formed a cluster with other species. Their results show Bocaccio, Canary Rockfish, and Yelloweye Rockfish were part of a nonflatfish shelf grouping that included Yellowtail Rockfish (Sebastes flavidus), Sharpchin Rockfish, and Lingcod. In the late 1980 s, when the data used by Rogers and Pikitch (1992) were being collected, thousands of metric tons of Bocaccio, Canary Rockfish, and Yelloweye Rockfish were being landed each year. That level of fishing is 
Table 4

Species clusters produced by hierarchical cluster analysis and based on data that were stratified into $1^{\circ}$ latitudinal intervals. The clusters are shaded or enclosed in solid or dashed lines to make the table easier to read. Group A (light gray), C (dark gray) and G (surrounded by dashed line) represent slope species, and group B (medium gray), D (enclosed in solid lines), E (surrounded by dashed line), and F (surrounded by dashed line) represent primarily shelf species. Only species that formed identifiable clusters were included in the table.

\begin{tabular}{|c|c|c|c|c|c|c|c|c|c|c|c|c|c|c|c|}
\hline \multirow[b]{2}{*}{ Species } & \multicolumn{15}{|c|}{ Latitudinal intervals (in ${ }^{\circ}$ North) } \\
\hline & $\begin{array}{l}34- \\
35^{\circ}\end{array}$ & $\begin{array}{l}35- \\
36^{\circ}\end{array}$ & $\begin{array}{l}36- \\
37^{\circ}\end{array}$ & $\begin{array}{l}37- \\
38^{\circ}\end{array}$ & $\begin{array}{l}38- \\
39^{\circ}\end{array}$ & $\begin{array}{l}39- \\
40^{\circ}\end{array}$ & $\begin{array}{l}40- \\
41^{\circ}\end{array}$ & $\begin{array}{l}41- \\
42^{\circ}\end{array}$ & $\begin{array}{l}42- \\
43^{\circ}\end{array}$ & $\begin{array}{l}43- \\
44^{\circ}\end{array}$ & $\begin{array}{l}44- \\
45^{\circ}\end{array}$ & $\begin{array}{l}45- \\
46^{\circ}\end{array}$ & $\begin{array}{l}46- \\
47^{\circ}\end{array}$ & $\begin{array}{l}47- \\
48^{\circ}\end{array}$ & $\begin{array}{l}48- \\
49^{\circ}\end{array}$ \\
\hline Dover sole & A & A & A & A & $\mathrm{A}$ & A & A & A & A & A & A & $\mathrm{A}$ & A & A & A \\
\hline Sablefish & A & $\mathrm{A}$ & $\mathrm{A}$ & $\mathrm{A}$ & A & A & $\mathrm{A}$ & A & $\mathrm{A}$ & $\mathrm{A}$ & A & A & A & A & A \\
\hline Shortspine Thornyhead & A & A & A & $\mathrm{C}$ & $\mathrm{A}$ & A & A & A & A & $\mathrm{A}$ & $\mathrm{C}$ & A & $\mathrm{C}$ & A & \\
\hline Longspine Thornyhead & & $\mathrm{A}$ & $\mathrm{A}$ & $\mathrm{C}$ & A & A & $\mathrm{A}$ & $\mathrm{A}$ & & $\mathrm{C}$ & $\mathrm{C}$ & & $\mathrm{C}$ & & \\
\hline \multicolumn{16}{|l|}{ Pacific Grenadier } \\
\hline Pacific Halibut & & & & & & & & & & & B & & & A & A \\
\hline \multicolumn{16}{|l|}{ Pacific Cod } \\
\hline Petrale Sole & A & & B & B & B & B & $\mathrm{B}$ & & B & B & B & $\mathrm{B}$ & B & B & A \\
\hline English Sole & & $\mathrm{B}$ & & B & $\mathrm{B}$ & B & $\mathrm{B}$ & & $\mathrm{B}$ & $\mathrm{B}$ & $\mathrm{B}$ & $\mathrm{F}$ & B & B & A \\
\hline Lingcod & & & & & B & B & B & & B & B & B & $\mathrm{F}$ & & B & $\mathrm{A}$ \\
\hline Bocaccio & B & B & & & & & & & & & & & & & \\
\hline Sanddabs & B & & & B & & & & & & $\mathrm{F}$ & & & & & \\
\hline Pacific Sanddab & & & & B & & & & & & F. & B & $\mathrm{F}$ & & & \\
\hline Spotted Ratfish & $\mathrm{A}$ & & B & $\mathrm{B}$ & $\mathrm{D}$ & $\mathrm{D}$ & & & & $\mathrm{B}$ & $\mathrm{A}$ & $\mathrm{B}$ & B & $\mathrm{B}$ & A \\
\hline Pacific Spiny Dogfish & & & B & B & & $\mathrm{D}$ & & & & & & & A & A & A \\
\hline Longnose Skate & A & $\mathrm{A}$ & B & A & $\mathrm{A}$ & $\mathrm{D}$ & $\mathrm{D}$ & $\mathrm{D}$ & & $\mathrm{A}$ & & & & A & \\
\hline Skates & & & & & & & & & & $\mathrm{A}$ & $\mathrm{A}$ & & & & A \\
\hline Pacific Hake & $\mathrm{A}$ & $\mathrm{A}$ & B & A & $\mathrm{D}$ & $\mathrm{D}$ & $\mathrm{D}$ & $\mathrm{D}$ & A & A & A & $\mathrm{A}$ & A & & \\
\hline Rex Sole & A & & B & B & $\mathrm{D}$ & $\mathrm{D}$ & $\mathrm{D}$ & $\mathrm{D}$ & $\mathrm{D}$ & $\mathrm{A}$ & A & $\mathrm{B}$ & B & B & A \\
\hline Arrowtooth Flounder & & & & & $\mathrm{D}$ & $\mathrm{D}$ & $\mathrm{D}$ & $\mathrm{D}$ & $\mathrm{D}$ & $\mathrm{A}$ & $\mathrm{A}$ & $\mathrm{A}$ & A & A & $\mathrm{A}$ \\
\hline Splitnose Rockfish & A & & & & $\mathrm{D}$ & & & & & & & & $\mathrm{G}$ & $\mathrm{G}$ & \\
\hline Pacific Ocean Perch & & & & & & & & & & & & & $\mathrm{G}$ & $\mathrm{G}$ & \\
\hline Redbanded Rockfish & & & & & & & & & & & & & & $\mathrm{G}$ & \\
\hline Greenstriped Rockfish & & & & & & & $\mathrm{E}$ & & & & & & & & \\
\hline Canary Rockfish & & & & & & & $\mathrm{E}$ & & & & & & & & \\
\hline
\end{tabular}

in stark contrast to more recent fishery trends. Bocaccio, Canary Rockfish, and Yelloweye Rockfish were declared overfished in the early 2000s. Landings of these species, particularly the latter 2 fishes, have since been tightly regulated, and many of the areas where they were known to have been caught have been closed to fishing. As a result of that regulation and of declining population trends, these species were extremely rare in fisheries catch observed from 2002 through 2009.

Despite their rarity, all rebuilding species except for Yelloweye Rockfish formed nonrandom groupings relative to their observed percent occurrence. This finding indicates that even though the ability to predict bycatch of rebuilding species is limited because of their rare occurrence, there may be a possibility to predict species composition specifically from tows where bycatch of rebuilding species occurs. A possible exception may be the Yelloweye Rockfish, which grouped randomly even at low encounter rates. Further research is needed to identify whether bycatch of this species can be tied to other variables beyond species composition.

When all species were included in the analysis, relationships between rebuilding species and other groundfish were not evident at large spatial scales. However, some groupings occurred when data were used from a smaller geographic range. Specifically, rebuilding rockfish formed groups most readily when the data were analyzed separately for each port group. It was difficult to tell whether the clusters formed in these cases were an artifact of error introduced by a smaller sample size, or whether the data were simply isolated temporally and spatially in a way that effectively allowed the recognition of the temporal and spatial structure of species assemblages. The propensity of rebuilding species to form clusters appeared to be a function of sample size. When the subset of data used had a small sample size but included catch of rebuilding species, bycatch of those species became less rare. That said, it is possible that because of the use of departure port, rather than standard latitudinal intervals, to stratify the data, the 


\section{Table 5}

Species clusters produced by hierarchical cluster analysis with data that were stratified by the departure port of fishing vessels. Different groups were shaded or enclosed in solid or dashed lines to make the table easier to read. Only species that formed identifiable clusters were included in the table. Groups A and B represent the slope and shelf clusters, respectively, which were also evident on a coastwide basis (Table 2). Group C represents the separate slope rockfish assemblage that formed for some northern ports. For some ports, Shortspine Thornyhead and Longspine Thornyhead formed a distinct group, which is represented in the table as Group D. Groups E, F, and G were smaller, distinct shelf species assemblages that were evident in the catch of vessels originating from some ports in Oregon and California.

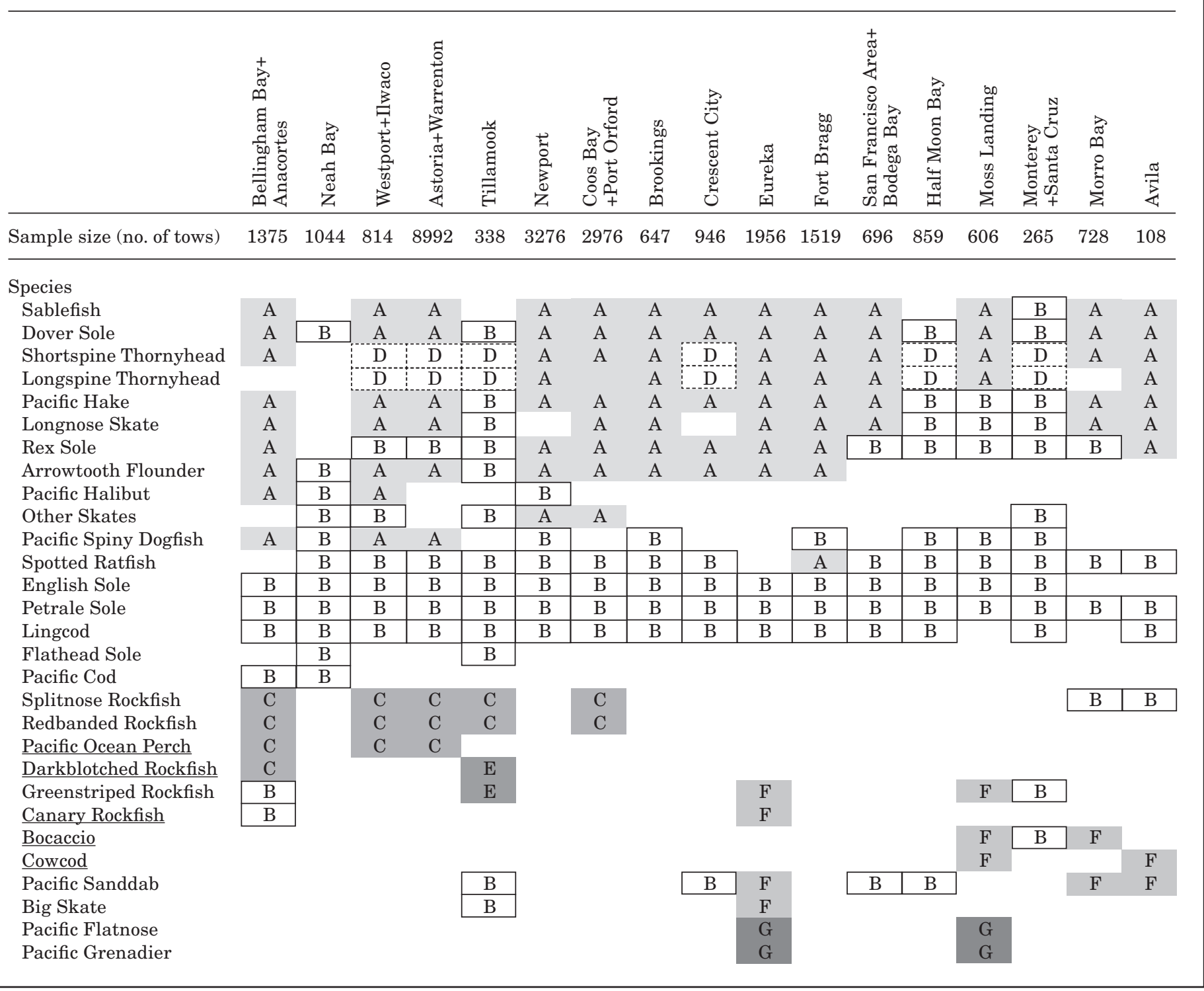

analysis more effectively identified species assemblages on local fishing grounds that were frequented by vessels from the same port. Indeed, vessels departing from Avila, where Cowcod was closely associated with $\mathrm{Pa}-$ cific Sanddab, appeared to fish within an area typically ranging less than a degree in latitude. Similarly, the range of depths fished by vessels departing from Monterey was typically less than $180 \mathrm{~m}$.
The data used in our analysis were from commercial catches and our results, therefore, reflect species assemblage patterns specifically as they pertain to fisheries. The data and sampling method used in our analyses likely miss finer-scale ecological patterns. Fine-scale ecological information that relates to species occurrences could provide further insight into the association of bycatch and target species, although col- 
lection of such information over a spatial scale that matches the fishery would be challenging.

If the same species clusters continue to be identified for each departure port as more data become available, they may provide evidence to support a more localized approach in the data analyses that support fishery management. Currently, bycatch data analyses in the bottom trawl fishery are structured to support managers who are responsible for implementing management measures over a vast area, from northern Washington to southern California (Bellman and Heery, 2013). The measures developed by managers have historically included a combination of trip limits, area closures, gear restrictions, and other approaches (King et al., 2004, Bellman et al., 2005; Branch, 2006). Regulations are often developed through the use of fishery data that have been stratified into a series of smaller management areas. However, even at this level, the measures put in place may be formed on the basis of fishery information from an area spanning hundreds of kilometers and may therefore affect vessels from a variety of different ports (Bellman and Heery, 2013).

This is not to say that large-scale management is ineffective. Fishery managers often rely on bycatch ratios to set bimonthly trip limits and closures of a given area to fishing. Even if species assemblages containing rebuilding and other nontarget species are not evident at the scale being used by managers, the bycatch ratios calculated for these areas should still provide an accurate large-scale representation of bycatch. However, more specific measures that relate bycatch of rebuilding species to catch or landings of a smaller subset of target species may be more relevant if developed through the use of fishery data specific to each port. For instance, bycatch of Darkblotched Rockfish and Pacific Ocean Perch may be more accurately estimated for northern ports by using catch of other deepwater rockfish species as a proxy for fishing effort. However, in other neighboring ports, this relationship with other deepwater rockfish species may not be relevant. For this approach to be effective, more data would need to be collected onboard fishing vessels so that potential species assemblages noted in this analysis can be confirmed and monitored over time. More data have become available since the 2011 implementation of the catch shares program (Toft et al., 2011), which required $100 \%$ observer coverage. Localized species assemblages identified from this new, more comprehensive data set, by using the methods presented here, could provide considerable insight to fishery managers as they continue to develop measures aimed at reducing bycatch of rebuilding species.

\section{Conclusions}

Data from the West Coast Groundfish Observer Program provided valuable insight into whether there were associations between target and nontarget groundfish species harvested commercially in the west coast demersal trawl fishery. Although many target species formed identifiable clusters, most rebuilding species did not form groupings. This characteristic of rebuilding species may complicate the use of bycatch ratios for fishery management purposes. We used a simulation approach to separate the effect of low rates of occurrence of rebuilding species from the actual tendency of these species to group with target species in cluster analyses. Our findings indicate that, although bycatch relationships between target and rebuilding species offer low predictive potential when coastwide data are used collectively; such relationships may be useful for predicting bycatch for specific port groups or for estimating bycatch amounts on tows when rare bycatch events do actually occur.

\section{Acknowledgments}

We are grateful to the fishery observers who have compiled tremendously valuable data through hard work and dedication. We also thank observer program staff for their support, M. Bellman for her central role in the processing of the data used in our study and for providing the map figure, and J. Majewski for the comments and insight she provided for the manuscript.

\section{Literature cited}

Alverson, D. L., M. H. Freeberg, S. A. Murawski, and J. G. Pope.

1994. A global assessment of fisheries bycatch and discards. FAO Fish. Tech. Pap. 339, 233 p. FAO, Rome.

Beddington, J. R., D. J. Agnew, and C. W. Clark.

2007. Current problems in the management of marine fisheries. Science 316:1713-1716.

Bellman, M. A., S. A. Heppell, and C. Goldfinger.

2005. Evaluation of a US west coast groundfish habitat conservation regulation via analysis of spatial and temporal patterns of trawl fishing effort. Can. J. Fish. Aquat. Sci. 62:2886-2900.

Bellman, M. A., and E. Heery.

2013. Discarding and fishing mortality trends in the U.S. west coast groundfish demersal trawl fishery. Fish. Res. 147:115-126.

Branch, T. A.

2006. Discards and revenues in multispecies groundfish trawl fisheries managed by trip limits on the U.S. West Coast and by ITQs in British Columbia. Bull. Mar. Sci. 78:669-690.

Clark, L. A., and D. Pregibon.

1992. Tree-based models. In Statistical models in S (J. M. Chambers and T. J. Hastie, eds.), p. 377-419. Wadsworth and Brooks, Pacific Grove, CA.

Collie, J. S., G. A. Escanero, and P. C. Valentine.

1997. Effects of bottom fishing on the benthic megafauna of George's Bank. Mar. Ecol. Prog. Ser. 155:159-172.

Cope, J. M., and M. A. Haltuch.

2012. Temporal and spatial summer groundfish assem- 
blages in trawlable habitat off the West Coast of the USA, 1977 to 2009. Mar. Ecol. Prog. Ser. 451:187-200. Cope, J. M., and A. E. Punt.

2009. Drawing the lines: resolving fishery management units, with simple fisheries data. Can. J. Fish. Aquat. Sci. 66:1256-1273.

Dayton, P. K., S. F. Thrush, M. T. Agardy, and R. J. Hofman. 1995. Environmental effects of marine fishing. Aquat. Conserv.: Mar. Freshw. Ecosyst. 5(3):205-232.

Gabriel, W. L., and A. V. Tyler.

1980. Preliminary analysis of Pacific coast demersal fish assemblages. Mar. Fish. Rev. 42(3-4):83-88.

Goni, R.

1998. Ecosystem effects of marine fisheries: an overview. Ocean Coast. Manage. 40:37-64.

Gordon, A. D.

1999. Classification, $2^{\text {nd }}$ ed., 272 p. Monographs on statistics and applied probability 82. Chapman \& Hall/

Jay, C. V CRC, Boca Raton, FL.

1996. Distribution of bottom-trawl fish assemblages over the continental shelf and upper slope of the U.S. west coast, 1977-1992. Can. J. Fish. Aquat. Sci. 23:1203-1225.

Jennings, S., and M. J. Kaiser.

1998. The effects of fishing on marine ecosystems. Adv. Mar. Biol. 34:201-210.

Kauffman, L., and P. J. Rousseeuw.

2005. Finding groups in data: an introduction to cluster analysis, 368 p. John Wiley \& Sons, Inc., Hoboken, NJ.

Keller, A. A., J. R. Wallace, B. H. Horness, O. S. Hamel, and

I. J. Stewart.

2012. Variations in eastern North Pacific demersal fish biomass based on the U.S. West Coast groundfish bottom trawl survey (2003-2010). Fish. Bull. 110:205-222.

King, S. E., R. W. Hannah, S. J. Parker, K. M. Matteson, and

S. A. Berkeley.

2004. Protecting rockfish through gear design: development of a selective flatfish trawl for the U.S. west coast bottom trawl fishery. Can. J. Fish. Aquat. Sci. 61:487-496.

Lee, Y.-W., and D. B. Sampson.

2000. Spatial and temporal stability of commercial groundfish assemblages off Oregon and Washington as inferred from Oregon trawl logbooks. Can. J. Fish. Aquat. Sci. 57:2443-2454.

Mahon, R., S. K. Brown, K. C. T. Zwanenburg, D. B. Atkinson,

K. R. Buja, L. Claflin, G. D. Howell, M. E. Monaco, R. N. O'Boyle, and M. Sinclair.

1998. Assemblages and biogeography of demersal fishes of the east coast of North America. Can. J. Fish. Aquat. Sci. 55:1704-1738.

Pauly, D., V. Christensen, R. Froese, and M. L. Palomares. 2000. Fishing down aquatic food webs. Am. Sci. $88: 46-51$.
Pikitch, E. K., C. Santora, E. A. Babcock, A. Bakun, R. Bonfil, D. O. Conover, P. Dayton, P. Doukakis, D. Fluharty, B. Heneman, E. D. Houde, J. Link, P. A. Livingston, M. Mangel, M. K. McAllister, J. Pope, and K. J. Sainsbury.

2004. Ecology: ecosystem-based fishery management. Science 305:346-347.

$\mathrm{R}$ Development Core Team.

2011. R: a language and environment for statistical computing. R Foundation for Statistical Computing, Vienna, Austria. [Available from http://www.r-project. org.]

Restrepo, V. R., G. G. Thompson, P. M. Mace, W. L. Gabriel, L. L. Low, A. D. MacCall, R. D. Methot, J. E. Powers, B. L. Taylor, P. R. Wade, and J. F. Witzig.

1998. Technical guidance on the use of precautionary approaches to implementing National Standard 1 of the Magnuson-Stevens Fishery Conservation and Management Act. NOAA Tech. Memo. NMFS-F/SPO-31, $54 \mathrm{p}$.

Rochet, M-J., and V. M. Trenkel.

2005. Factors for the variability of discards: assumptions and field evidence. Can. J. Fish. Aquat. Sci. 62:224-235.

Rogers, J. B., and E. K. Pikitch.

1992. Numerical definition of groundfish assemblages caught off the coasts of Oregon and Washington using commercial fishing strategies. Can. J. Fish. Aquat. Sci. 49:2648-2656.

Thrush, S. F., and P. K. Dayton.

2002. Disturbance to marine benthic habitats by trawling and dredging: implications for marine biodiversity. Annu. Rev. Ecol. Syst. 33:449-473.

Toft, J. E., A. E. Punt, and L. R. Little.

2011. Modelling the economic and ecological impacts of the transition to individual transferable quotas in the multispecies US west coast groundfish trawl fleet. ICES J. Mar. Sci. 68:1566-1579.

Tolimieri, N., and P. S. Levin.

2006. Assemblage structure of eastern Pacific groundfishes on the U.S. continental slope in relation to physical and environmental variables. Trans. Am. Fish. Soc. 135:317-332.

Weinberg, K. L.

1994. Rockfish assemblages of the middle shelf and upper slope off Oregon and Washington. Fish. Bull. 92:620-632.

Williams, E. H., and S. Ralston.

2002. Distribution and co-occurrence of rockfishes (family: Sebastidae) over trawlable shelf and slope habitats of California and southern Oregon. Fish. Bull. 100:836-855.

Zimmerman, M.

2006. Benthic fish and invertebrate assemblages within the National Marine Fisheries Service US west coast triennial bottom trawl survey. Cont. Shelf Res. 26:1005-1027. 